that reached by British first-degree honours students. In their final year, the students are required to carry out advanced practical work of a semi-research nature, and to write a dissertation. Some of this practical work being carried out in Poking included a number of studies on the Hall effect, magnetic domains, the measurement of the refractive index of gases using an interferometer method, the study of beta-ray spectra using a cloud chamber with magnetic fiold, and soveral X-ray crystallographic studies. One of tho final-year theoretical physics studonts suid he had just written his dissertation on the influence of detailed well-shape in the 'cloudy crystal' nuclear model.

The curriculum of the proposed five-yoar course is set out in Iable 1. Each year is divided into two semesters of eighteen weeks and seventeen weeks duration, respectively, and the table shows the time devoted to the study of various subjects.

An impressivo foature of the instructional system is the care taken of the student as an individual. During the first two or three years of his course, a member of staff acts as tutor to a student, guides him in his courso and has the task of teaching him how to study. Tho supervisor must also ensuro that no student spends more than fifty-four hours a week in all studies, including home study. In the fourth and fifth years, tho students are organized into groups, under a student group-leader.

From the third year onwards, 'term papers' are set which involve the proparation of answers based on the reading of original papers, and the studont is expected to spend about twenty-four hours in each semester working on them. In this way, experience is gained in the use of reference libraries, and the student, by the time his fifth year is reached, should be in a position to work on the problem set for his thesis.

Great care is devoted to the examination of students. All university examinations, including the final, are oral. Each year, three weeks in the first semester, and four weoks in the second, are devoted to oral examining of students. Just prior to the examination, the student draws a number of questions he will be expected to answer from a hat. He then has half-an-hour in which to colloct his thoughts and consult references before presenting himself for the actual examination, which is carried out by the teacher who took the course and which may last 20-25 min. This system, which closely follows the procedure long in use in Soviet universitios, appears to be working quite satisfactorily. More than 80 per cent of all students oxamined receive the classification 'excellent' or 'very good'. At tho ond of his course the student is required to defend his thesis at an oral examination.

This examining imposos a considerable burden on the teaching staff; indeed, owing to the shortage of teachers, those able to teach have had to do so for much longer hours than is desirable. The supply of good university teachers is ono of the most difficult problems that is being faced. Now that the first generation of students is graduating, howevor, some of whom will be offered university teaching posts, it is expected that the strain of excessive teaching will be greatly reduced. Indeod, university teachers have been promised that in future it will be regarded as normal for 25 per cent of their working time to be spent on teaching, the remainder being devoted to research.

Some research in solid-state physics and in crystal lography was being carried out at the universities visited ; but in this connexion, our visit to tho Nuclear Physics Section of the Physics Institute of the Academia Sinica was of greater interest. Although it has boen operating for only a fow yoars, it has a staff of more than a hundred scientists and technicians, and work was proceeding with the development of most of the modern techniques used in nuclear physics. There was, for example, a cloud chamber, of diameter approximately $25 \mathrm{~cm}$. with a magnetic field of 10,000 gauss, and a multiplate chamber $50 \mathrm{~cm}$. square which had been operated for two years at mountain altitudes. About 50,000 pictures had been taken with it, and some examples of associated production of hyperons and $K$-mesons, as well as other interesting events obtained. 'Tho quality of the work was impressivo.

A pressurized Van do Graaff machine, together with acceleration tube to yield particles of energy $2 \mathrm{MeV}$., has beon constructed, together with a high-tension gonorator employing a Cockeroft-Walton circuit. For work on beta-ray spectroscopy, a two-lons spectrometer has been constructed. A large group was working on problems of the production and use of scintil. lation counters, while anothor group was using nucloar emulsions which they themselves had made. Although not as good as the Ilford Company's elcetron-sensitive emulsions, plates had already been produced which were able to detect particles of twice minimum ionization.

Many of the prosent workors at the Institute have been trained in Europe or the United States and are well informed about new developments. But more physicists are groatly neoded at the Institute and throughout the country. It says something for the insistence on quality of training that, faced with this position, resort has not boen mado to dilution of courses; and in tho rosearch work in nuclear physics, too, grest stress is boing placed on building a sure and solid foundation so that eventually one may expect work of the highest quality to issue from the Institute.

The scientific probloms of China are immense. But they are being approached with such energy and intelligence that there seems little doubt that the China of the future will have much to contribute to world science.

\section{STUDY OF FERTILITY}

$\mathrm{T}$ HE seventh annual conference of the Society for the Study of Fertility was held during June 1415 at the meeting house of the Zoological Socioty of London and at the National Institute for Medical Research. Eighteen papers wero read, and nine of those dealt chiefly with clinical aspects of human infertility. 'L'he remaining nine papers were of more genersl scientific interest and were communicated by the following investigators.

Dr. J. W. Goldzieher (San Antonio, Texas) described recent work on stallion semen at the Soutb-west Foundation for Resoarch and Educa. tion, in which it was found that the semen from some infertile stallions contained apparently normal spermatozoa. Further investigation showed that the motility and fertility of spermatozoa depended as much upon properties of the seminal plasma as upon the vitality of the spermatozoa themselves, and that the quality of the plasma varied greatly between different animals. This was demonstratod by sep. areting the cells from the plasma by centrifugation and then suspending tho spermatozos from one 
stallion in the plasma from other stallions. Seminal plasma from some animals supported motility better than that from others, and this property was inversely related to the concentration of sulphydryl compounds. The incidence of pregnancy also was inversely related to the concentration of these substances in the semen.

Dr. J. Hammond (Cambridge) reported investigations on the degeneration of foetuses during the later stages of pregnancy in the rabbit. The occurrence of foetal atrophy and the proportion of foetuses lost were evidently related to a maternal character that could be selected for by appropriate breeding experiments. The inheritance of the character took place in the manner of a genetic recessive and found more obvious expression in animals in which larger numbers of eggs were shed. There was evidence for the operation of the same mechanism in sheep when the number of eggs shed was increased by the administration of hormones. Dr. Hammond believes that foetal atrophy is not a reflexion of limited space within the uterus but can be ascribed to the relative deficiency in the uterus of some substance required for normal fotal development. The nature of the substance is as yet unknown.

Dr. A. Walton (Cambridge) described an apparatus developed in collaboration with $\mathrm{Mr}$. H. M. Dott wherein a semen sample is held within a 'Cellophane' tube around which an artificial medium can be circulated. The properties of the medium can be varied at will so that the influence upon the spermatozoa of temperature, hydrogen-ion concentration, gas tension and diffusible substances can be studied without the need for dilution of the spermatozoon suspension directly with the artificial medium. When spermatozoa derived from the epididymis were placed in the apparatus, it was possible to show that the initiation of motility was due to the presence of both oxygen and fructose in the surrounding medium. The effect of the accessory secretions could be ascribed to their content of these substances. Nitrogen inhibited the motility and this inhibition could later be reversed by supplying oxygen.

Dr. I. G. White (Sydney) gave an account of investigations on the effect on spermatozoon motility of composition of the medium, concentration of spermatozoa, and temperature. The buffering of diluting media was particularly important under anaerobic conditions owing to the production of lactic acid. The output of lactic acid varied with the amount of phosphate present, because high concentrations of phosphate decreased the ability of the spermatozoon to oxidize lactic acid. Potassium tended to improve motility, and traces of copper and iron were probably not detrimental. Most chelating agents tested were toxic; cobalt decreased the toxicity of some. The 'dilution effect' was referable to the loss of substances from the spermatozoon, and these may include biotin and cytochrome c. The presence of lipo-protein in egg-yolk mitigates the loss. 'Cold-shock' was associated with a drop in the adenosine triphosphate content of the spermatozoon. Some protection was afforded by egg-yolk owing probably to the presence of lecithin and similar compounds. Antibiotics were in general well tolerated by spermatozoa. When spermatozoa were rewarmed after deep-freezing, some metabolism of the added glycerol occurred under anaerobic conditions. Ram semen contains 1 or 2 per cent of glycero-phosphatyl choline.

Miss Clare Harvey (Exeter) said that detailed and systematic examinations of early and late fractions of human semen showed that the early fraction, though often very small, contains the majority of the spermatozoa. She believes that in the pre-ejaculatory phase of excitement a dense mass of fresh spermatozoa passes into the vas deferens and ampulla, where it is met by back-flowing prostatic secretion. The seminal vesicles then discharge, washing the rest of the spermatozoa through the ejaculatory duct. The function of prostatic citric acid in man may be to inhibit coagulation and permit the ready escape of spermatozoa in the female tract, and the function of coagulation in the late fraction may be to prevent dilution of the early fraction.

Mr. G. A. Harrison (Liverpool) reported that mice kept in a hot environment (dry bulb $90^{\circ} \mathrm{F}$., wet bulb $84^{\circ} \mathrm{F}$.) bred normally ; but the females failed to suckle unless they had been brought up under the same conditions. There was thus evidence of adaptation to the high temperature. Adapted animals also survived longer when exposed to temperatures (dry bulb $104^{\circ} \mathrm{F}$., wet bulb $84^{\circ} \mathrm{F}$.) that generally proved fatal in about $12 \mathrm{hr}$. Survivors from such an experiment also showed no loss of fertility. Rats exposed to a dry-bulb temperature of $100^{\circ} \mathrm{F}$. suffered little or no damage to the testis. When water at $107^{\circ} \mathrm{F}$. was applied to the scrotum the testis temperature became constant at $103^{\circ} \mathrm{F}$. An environmental temperature of $107^{\circ} \mathrm{F}$., however, did not raise the testis temperature above $96^{\circ} \mathrm{F}$., although the abdominal temperature was $102^{\circ} \mathrm{F}$. The sorotum is therefore an important and efficient heat-disposing surface. This property was removed by covering the scrotum with paint, whereupon an environmental temperature of $100^{\circ} \mathrm{F}$. led to testicular damage.

Mr. J. H. Grant (Liverpool) said that he had studied the effects on the remaining testis of unilateral castration in rats. Following the operation, there was a compensatory increase in the growth-rate of the testis, and the final volume reached was greatly in excess of normal. The total number of .tubule cells, however, was not increased, nor was the amount of interstitial tissue. The ratio of the diameter of the lumen to the diameter of the whole tubule was also unchanged. The larger size reached by the testis is therefore imputed chiefly to hypertrophy of the tubule cells, although the Leydig cells, after an early decrease, did show some increase in number. Testosterone administration was found to inhibit the testis hypertrophy if applied in the first five weeks after the operation.

Prof. R. G. Harrison (Liverpool) described experiments in which solutions of chorionic gonadotrophin were injected into mature rats. In a control series, rats received injections of sterile distilled water. No effect was seen in the tubular epithelium, in the number of Leydig cells or in the amount of interstitial tissue; but there was an increase in the quantity of tissue fluid. 'Phytoid' vacuoles appeared in the spermatogonia, connoting an increase in cell fluid, and there was enlargement of spermatocyte nuclei. In addition, spermatogonia appeared to be reproducing spermatogonia in large numbers, for several layers of these cells were observed. These changes were seen in both experimental and control groups of rats and are interpreted as evidence of a stress reaction evoked by the injections.

Dr. M. W. H. Bishop (London) gave a short account, illustrated by colour transparencies, describing the application of fluorescent dyes, notably acridine orange, to the study of morphology in living spermatozoa. When the preparations are subjected 
to ultra-violet irradiation the spermatozoa exhibit a brilliant fluorescence, the acrosome appearing red or orange and the rest of the cell green. The large variations in the form of the acrosome in several species of mammals were thus clearly demonstrated. With the dye primuline a striking colour contrast is obtained between living and dead spermatozoa.

Demonstrations provided by the Division of Experimental Biology at the National Institute for Medical Research illustrated aspects of work on mammalian gametes and fertilization, reproduction in mice after ablation of the thyroid by iodine-131, gonadal geafts in the rat, production of aspermatogenesis in the guinea pig with testis antigen, and the effects on foetal development of exposure of the mother to severe hypothermia.

C. R. Austin

\section{EFFECT OF VARIOUS STIMULI ON TISSUES OF DIFFERENT AGES}

A

MEETING of the British Society for Research A on Ageing was held at the Ciba Foundation, London, on June 8, and a series of papers dealing with the effects of various stimuli on tissues of various ages was read.

The initial three papers were introduced by Prof. K. J. Franklin, under whose direction the work had been carried out. In the first paper, Dr. Sheila B. Carter, of the University of Bristol, dealt with the reaction of the gingival epithelium to friction in rats at different ages. She pointed out that, although some human experiments have been carried out in this field, work on animals may be more satisfactory since they may be kept on a standard diet under standard conditions and the amount of friction applied can be controlled. Dr. Carter used the merion rat (Meriones libycus) and three experimental groups : 5-4 months old ; 9-12 months ; and 14-16 months. In all groups the gum of the diastema between incisors and molar's of the right side of the upper jaw was rubbed with a brush consisting of a single nylon tuft about $4 \mathrm{~mm}$. long, for one minute twice daily for 4 weeks, the other side of the jaw being left as a control. The thickness of the cornified layer was afterwards measured in histological sections of the gum. The minimum width of the epithelium and the depth of the epithelial papillæ were also measured. The brushing caused a marked though variable increase (5-280 per cent) in the thickness of the cornified layer. At the same time, the minimum width of the epithelium tended to increase though not significantly; but there was a significant increase in the depth of the epithelial papillæ. It was of interest that there was no correlation between age and any histological change.

It is hoped to extend this work to a study, in the Physiology Department of St. Bartholomew's Hospital Medical College, London, of the clinical effects of mechanical friction on the human gum, and in this connexion Dr. F. J. Aumonier gave an account of his preliminary studies of the human gum. He demonstrated a striking variability in the pattern of the epithelium in human jaws which varied enormously from one side to the other in the mouth, at various levels near the teeth and in the projections of gum between the teeth. Before these clinical studies can be commenced, therefore, a very full study will have to be carried out on the variations in average thickness of gum, minimum and total thickness of the cornified epithelium, resistance to infection, etc., of the human gum in different parts of the mouth.

Dr. Patricia Lindop, of the Nuffield Gerontological Unit at the Department of Physiology, St. Bartholomew's Hospital Medical College, described three pilot experiments used in the study of the roles of whole organs in the process of ageing. The first of these dealt with the rabbit kidney, which was studied in relation to the weight of tissue and blood content at various ages. The latter was determined by using a perfusion method-washing out red cells which had been labelled in vitro with radioactive phosphorus. The renal blood content was determined within an accuracy of 2 per cent, and was found to be remarkably constant for animals of the same proportionate weight of renal tissue. In the rabbit Dr. Lindop also demonstrated that there is a distinet correlation between the weight of renal tissue and the whole body weight-that is, the smaller the animal the larger is the proportion of renal tissue. The normal renal blood content shows a parallel decrease ranging from $50 \mathrm{per}$ cent in the neonatal period to 41 per cent between weaning and puberty, and thereafter 31 per cent in adult life with no definite decrease even at three years.

The second experiment carried out by Dr. Lindop was a study of the uptake of radioiodine in 246 rats of different ages (1 day -47 weeks old). No significant difference in rate of uptake nor in the total amount of iodine taken up by the gland was recorded, although if older animals had been studied a change might have been found.

In the third series, eighty-five elderly patients between sixty-five and ninety-five years of age were studied in relation to their renal function following a period of hypotensive anæsthesia for prostatectomy. The aim of this study was to determine whether hypotension with vasodilatation, as occurs with vasomotor paralysis, is less harmful to the senile patient with reduced cardiac, cerebral and renal reserves than hypotension with vasoconstriction occurring during hæmorrhage at operation. It was found that a fall in blood pressure to a level of $80 \mathrm{~mm}$. (of mercury) systolic was optimum. There was no impairment of renal function unless the pressure was dropped below $60 \mathrm{~mm}$., when there was a transient oliguria and a rise in blood urea post-operatively.

The final paper was read by Dr. Honor B. Fell, who pointed out that early work had shown that vitamin A deficiency had caused mucous membranes to undergo a squamous metaplasia and to keratinize. Previous work by Dr. Fell and the late Sir Edward Mellanby had shown that, whereas epidermis from the trunk and limbs of 6-7-day chick embryos differentiated into squamous keratinizing epithelium in a normal medium, it formed a mucus-secreting, often ciliated, membrane when grown in medium to which excess vitamin A had been added. Dr. Fell then went on to describe experiments designed to discover whether explants of older, more highly developed, skin would undergo similar transformation in response to excess vitamin A. The scaly skin of the shank and feet of 13- to 18-day chick embryos was used.

When grown in normal medium, the 13-day skin keratinized and maintained its normal structure; but in the presence of excess vitamin $A$, it underwent mucous metaplasia as readily as the 7-day epidermis. The 18-day skin had a fairly thick stratum coineum when first explanted ; in normal medium the keratin increased in thickness, but in the high vitamin A medium it became detached by swelling and sub. 